\title{
The Education Measurement Specific Effect on Sustainable Development: An Experience of Indonesia
}

\author{
Abdur Razzaq ${ }^{1}$ and Sari Lestari Zainal Ridho \\ ${ }^{1}$ Universitas Islam Negeri Raden Fatah Palembang, Indonesia, e-mail: \\ abdurrazzaq uin@,radenfatah.ac.id \\ ${ }^{2}$ Politeknik Negeri Sriwijaya, Indonesia, e-mail: sarilestari@polsri.ac.id
}

\begin{abstract}
: the sustainability development is a target to be achieved by any nations, it requires to have qualified human capital. While population`s level of education, especially those who work, are still relatively low. The failure in education indicates the failure in the education quality improvement, lack of school participation rate (SPR), net enrollment rate (NER) and the Gross Enrollment Rate (GER), as well as the average length of school. The purpose of this study was to what extent the achievement of Indonesia in sustainability development. For that the discussion of sustainability development would be reviewed from the contributions of several education indicators in Indonesia comparatively and several variables represented by the poverty alleviation or reduction. This comparative analysis was carried out in order to improve research model and to enlarge the knowledge within this field of research. The research methods were qualitative and quantitative approaches, multivariate regression analysis techniques, the condition of some education quality in Indonesia and some other variables in 2010. The results of this study indicated that there was a significant simultaneous influence of variables tested from the equation toward poverty reduction variable, specifically related to educational variables, partial effects were only shown by the education variables with the indicator of secondary school enrollment rates had effect, while the other educational indicators did not.
\end{abstract}

Keywords: Education, Human Capital, Sustainability Development

\section{Introduction}

Indonesia is a country with population potency of productive age is more than the non-productive age population and it should be able to make human capital as the sustainability development capital. As a conception-built base on the theory of bonus (dividend) demography (Bloom and Williamson, 1997), that in the initial stage, first demographic dividend, the demographic transition is a condition where there is an increase in productive age ratio and the decrease in dependency of non-productive age ratio. In the second stage, second demographic dividend, is a condition in which a transformation from a 'bonus' in the first stage becomes a greater asset and sustainability development (Silipo, 2009). However, based on Indonesia Central Statistical Bureau data, the working population in Indonesia in the period 2000-2014 was dominated by population with a low human capital. The working population in the period 2000-2014 was dominated by primary school education level, in 2000 there were $55,820,116$ people, in 2007: 56,368,930 people and 2014: 53,955,537 people. While the working population of graduated junior high school, senior high school and vocational high school less in numbers, in 2000, 2007 and 2014 respectively 30,039,692 people, 37,365,889 people, and 49,451,332 people. This is certainly affected toward the human capital productivity in the economic development process in Indonesia.

Gaps in the concept and the existing phenomena in Indonesia become the important reasons to conduct a study which examine the relationship between human capital and the economy, in particular the sustainability development. Although there are many previous studies that discuss the relationship between human development and the economy, but this research focused on the sustainability development by comparing the effects of several different education indicators, they are, secondary school enrollment rates, the school duration average and the literacy rate. 
Since it is based on the conception of demographic bonus and the existing phenomena in Indonesia, then the purpose of this study was to investigate the contribution of some education indicators in Indonesia comparatively towards the sustainability development with several other indicators that could be used as the achievement of the sustainability development represented by a poverty reduction.

The Sustainability Development. Development is known as a logical process of a change in society that cannot be separated with nature. Development is a universal property of the "nature-society" system and all of the components can be changes evolutionarily (gradually) or quickly (a sharp change). One of aspect that a country tries to develop is the economic development.

Economic development, based on the conventional theory is focused on the economy or synthesize theory of economic growth from the thoughts flow from the Keynesian, classical and neoclassical. In the developments there were thought development related to the economic development definition, which define the economic development as a gradual process (Epure, 2015). The concept of economic growth had been developed, including the concept of economic growth with equity (growth with equity), namely economic growth with equitable prosperity which can be enjoyed by many people through the increase of income and a standard of living (Feng, 2011). The growth with equity is also a policy in the development in Indonesia (Kuncoro, 2013).

The developments or paradigm changes about the economic development, resulting in changes in the sizes of the development process in a country. The development is not only based on national output measures, but also more important qualitative measures, such as the change growth in the values and institutions, the development process quality which are realized through the reduction of poverty, unemployment, and inequality (Kuncoro, 2013) .

The sustainability development (sustainability development) is the ability of system (either nature or social) to maintain the qualitative basic parameters during the development process. While the measurement of sustainability development is defined as a parameter evaluation of a country and system dynamics under supervision in connection with certain optimum characteristics (Mazurov \& Vladimir, 2006). Some indicators of sustainability development achievements such as: national income; economic growth; income per capita; national income distribution; poverty; and public health.

Public Welfare, Poverty Reduction, as the Sustainability Development Parameter. Besides Kuncoro (2013), the economists who also supported the idea that economic development is not only measured by how much output is produced nationally are Nasir and Tahir (2011). They agreed that economic growth could be measured by the poverty reduction. Considering the conception of growth with prosperity is consistent with Indonesian development objectives; then, the economic growth model with a society welfare approach measured by poverty is suitable to use. The poverty is influenced by the number of population (Orbeta, 2003), so that the birth rate and death rate are factors that affect the poor people numbers. The great of the dependency age ratio, that the greater ratio of not-labor force age will increase the poor people numbers since more population must be supported rather than sustaining (Nasir and Tahir, 2011). Thus, the factor that will reduce the number of poor populations is the working population numbers. Another factor affecting the poor people numbers is the increase of life expectancy, which cause the working population work longer. (Silipo, 2009).

Education. Education is one component that can provide information about the condition of human capital quality or human resources possessed by a country. The quality of human resources can also be measured from the health and welfare. The calculation of these three elements can be summarized in a single index, known as the human development index. Based on data from the Central Bureau of Statistics, the Human Development Index (HDI) in Indonesia, showing that quality of human development in Indonesia had decreased in 1999 and 2002 when compared to the previous period. In 1996 HDI Indonesia was 67.70, then declined to 64.30, in 1999. In 2002 increased again to IDR 65.80, although showing an increase when compared to 1999 but lower than in 1996, later in 2010 HDI Indonesia increased to 72.27 . 
In the study the variable used as a measure of human capital was the education. The first human capital variable was education. It was one of the variables that represent the human quality (capital) and can be measured using various indicators. Some measuring devices used to indicate the level of education quality success were School Enrollment Ratio (SER), net enrollment ratio (NER) and the Gross Enrolment Ratio (GER), as well as average years of schooling.

School Enrollment Ratio (SER) is an indication of how much the access of the school age population can enroll formal education in schools. Net Enrollment Ratio (NER) is a proportion indication of the school-age children go to school on time, and the Gross Enrolment Ratio (GER) is an indication of the population participation in getting education appropriate with their education levels.

The average years of schooling is also one of the quality indicators of human capital (Awan, et al., 2011) as it demonstrates the achievement of every society in the school activities. Based on the definition that the school duration averages the number of years spent by population aged 15 years and above to pursue any type of formal education, the higher number of school duration, the higher level of education has been achieved population.

Indicators of the human resource education quality also commonly used are the literacy rate (LR) (Smith \& Greenway, 2015) and illiteracy rate (IR). LR is a proportion of the population aged 15 years and above who have the ability to read and write Latin and other letters, without having to understand what is read / written to the population aged 15 years and above. While IR is the proportion of the population aged 15 years and above who do not have the ability to read and write Latin and other letters to the population aged 15 years and above. IR is one of the basic indicators used to see the achievement of an area, because reading is the main basis in boarding scientific knowledge so IR is an important indicator to look at the extent of the population in a region open to knowledge.

Based on BPS data, the number of years spent population aged 15 years and above to pursue any type of formal education ever undertaken by the Indonesian population constantly increased in the period 1996 to 2012. In 1996 the school duration average of Indonesian population was 6.3 year, continued rising to 7.1 in 2002, 7.52 in 2008 and 8.08 in 2012.

While the gross enrollment of secondary school (first) rate (GER), over the last 30 years showed an increasing trend, but there was a decline in 2010. Data in 1985, based on the Central Bureau of Statistics showed that gross enrollment of secondary school rate was 47.4 percent, in 1990 was 54.44 percent, while five years later, in 1995 (GER) of secondary school was 65.65 percent, next in succession in 2000, 2005 and 2010, GER of secondary schools in Indonesia were 77.62, 82.09 and 80,35 .

Furthermore, based on the National Social economic Survey and Education Indicators, BPS, the access of the school age population can get formal educations in schools in Indonesia declined in 2000, if compared to 10 years earlier, in 1990, but then increased again in 2010. In 1990 the school age population could get a formal education 69.25 percent, then decreased to 59,64 percent of the school age population could get formal educations in 2000, and then increased again in 2010 to 63.51 percent. Factors affecting fluctuations in the enrollment rates were the economic conditions and government policies.

The economic crisis that had occurred since the late 1997 triggered the reduced society ability to get formal educations, but then the government policy both central and local levels in the form of an increase in the education budget 20 percent since 2009, including in the form of School Operational Assistance (BOS), as well as free school tuition, expanding opportunities in access to formal educations, so that the school enrollment rate increased again in 2010.

\section{Research Methodology}

This study used the analysis unit of sustainability development in Indonesia with the poverty reduction indicators. The empirical studies were conducted by using statistical analysis media. This was a cross-sectional study, where data were available from the provinces in Indonesia and were gathered at one time, in 2010, from the sample selected. 
The type of data used were quantitative and qualitative study to discuss the sustainability development in various provinces in Indonesia and the factors influence it, the source of the data used in this research were secondary data obtained from the Central Bureau of Statistics. The data used were the birth rate, the dependency ratio, education (school enrollment rate average, the school duration average, and literacy rates), the working population, investment, and gross regional domestic product from various provinces in Indonesia in 2010 in which the data were available, namely a total of 33 provinces, as well as other data that supported this research. Data collection methods used in this research was the documentation method, which the data were collected through written documents, especially in the form of file and also included certain books, opinions, theories, or laws and others related to the research problem.

In this study, based on the theory previously described connected with relations between variables, sustainability development with poverty reduction indicators which were influenced by things: the birth rate, the dependency ratio, education (school enrollment rate average, the school duration average, literacy rates), the working population, investment, and gross regional domestic product. The following was the description of regression model as estimated:

$$
\begin{aligned}
& \text { POV }=a_{0}+a_{1} \text { TFR }+a_{2} \text { DR }+a_{3} \text { EDU1 }+a_{4} S R+a_{5} \text { DI }+a_{6} \operatorname{lnGDRP}+e_{1} \\
& \text { POV }=b_{0}+b_{1} \text { TFR }+b_{2} \text { DR }+b_{3} \text { EDU } 2+b_{4} \text { SR }+b_{5} \text { DI }+b_{6} \operatorname{lnGDRP}+e_{2} \\
& \text { POV }=c_{0}+c_{1} \text { TFR }+c_{2} \text { DR }+c_{3} \text { EDU } 3+c_{4} S R+c_{5} \text { DI }+c_{6} \ln \text { GDRP }+e_{3}
\end{aligned}
$$

Where:

POV is the percentage of poor population

EDU1 is the school enrollment rate

EDU2 is the average years of schooling

EDU3 is the literacy rate

TFR is the total of fertility rate

SR is the support ratio, the percentage of the working age population / total population

DR is the dependency ratio, the number of population aged $<15$ years/ total population

DI is the percentage of domestic / Investment Total

GDRP is the Gross Domestic Regional Product per capita

Regression models are made with the reason to carry out detailed and comparative analysis of human capital represented by education with a variety of different indicators with the aim of being able to specifically measure the impact on sustainable development. Furthermore, this comparative analysis was conducted in order to improve research model and to enlarge the knowledge within this field of research.

\section{Result and Discussion}

For the validation process, the Goodness-od-fit measure was used, that was coefficient of determination $\left(\mathrm{R}^{2}\right)$ and Mean Square Error (MSE). The coefficient of determination (R-Square) was defined as various endogenous variables which were capable to explain by exogenous variables simultaneously / together was as R-Square where the rest could be explained by error or other variables which was not included in the multivariate regression models. In other words, the goodness of the multivariate regression models was formed indicated by the value of R-Square. The greater the $\mathrm{R}$-square value, the better the multivariate regression models were formed. In addition, the measures goodness of the multivariate regression models used was MSE. To assess the measures goodness of the model, the formula of MSE measures was:

$$
M S E=R M S E^{2}
$$

RMSE value was obtained from the output of Root MSE value, as shown in Table 1. 
Table 1. Results of Multivariate Regression Model Validation

\begin{tabular}{lcll}
\hline Equation & R-Square & Root MSE & MSE \\
\hline POV1 & 0,6849 & 5,12883 & 26,3049 \\
POV2 & 0,6538 & 5,376098 & 28,90243 \\
POV3 & 0,6545 & 5,370642 & 28,8438 \\
\hline
\end{tabular}

Source: Research Data Processed, 2016

While based on the output result in Table 2, this test gave a conclusion that there was a simultaneous significant influence predictor variables of the equation POV1, POV2, and POV3 toward the response variable POV. In testing the partial / individual coefficient model with t-test, it gave a significant influence when the value of P-value $\leq \alpha$ with $\alpha$ was determined by at $10 \%, 5 \%$, or $1 \%$.

From the output results in Table 2, this test gave conclusions that:

1. There was a significant influence of variable DR to POV each 1.070551 (positive effect) on equation POV1; meaning that if there was an increase of 1 unit of the Dependency Ratio, the increase in the value of Percentage of Poor population number was 1.070551; and vice versa if there was a decrease of 1 unit of Dependency Ratio, the decrease in Percentage of poor population was 1.070551 .

2. There was a significant influence of variable EDU1 to POV 0.2077121 (positive effect) on equation POV1; meaning that if there was an increase of 1 unit on the school participation rate, the increase in the percentage of Poor population number was 0.2077121 ; and vice versa if there was a decrease of 1 unit of school participation rate, the decrease Percentage of Poor population number was 0.2077121 .

3. There was a significant influence of variable SR to POV 0.5236898 (positive effect) on equation POV1; meaning that if there was an increase of 1 unit of Support Ratio, the increase in the value of Percentage of Poor Population numbers was 0.5236898; and vice versa if there was a decrease of 1 unit of Support Ratio, the decrease Percentage of Poor Population numbers was 0.5236898.

4. There was a significant influence of variable lnGDRP to POV -6.281613 (negative effect) on equation POV1; meaning that if there was an increase of one unit of the GDRP Natural logarithm, the decrease Percentage of Poor Population number was 6.281613; and vice versa if there was a decrease of 1 unit of the GDRP Natural logarithm, the increase in the value of Percentage of Poor Population numbers was 6.281613.

5. There was no significant influence of variable TFR and PDMN to POV on the equation POV1; meaning that if there was an increase / decrease of 1 unit of Total Fertility rate and Percentage of Total Capital Investment, the percentage Poverty rates would not be affected.

6. There was a significant influence of variable POV to DR each at 1.085727 (positive effect) on equation POV2; meaning that if there was an increase of 1 unit on the Dependency Ratio, the increase in the value of Percentage Poor population number was respectively 1.085727; and vice versa if there was a decrease of 1 unit of the Dependency Ratio, the decrease of Percentage of Poor Population number was 1.085727 .

7. There was a significant influence of variable SR to POV 0.5527158 (positive effect) on equation POV2; meaning that if there was an increase of 1 unit of Support Ratio, the increase in the value of Percentage Poor population number was 0.5527158; and vice versa if there was a decrease of 1 unit of Support Ratio, the decrease of Percentage of Poor Population numbers was 0.5527158.

8. There was a significant influence of variable lnGDRP to POV -6.049876 (negative effect) on equation POV2; meaning that if there was an increase of one unit of the GDRP Natural logarithm, the decrease of Percentage of Poor Population number was 6.049876; and vice versa if there was a decrease of 1 unit of the GDP Natural logarithm, the increase of Percentage of Poor Population numbers was 6.049876 .

9. There was no significant influence of variable TFR, EDU2, and DI to POV on equation POV2; meaning that if there was an increase / decrease of 1 unit of Total Fertility Rate, average years of 
schooling, and Percentage of Total Capital Investment, the percentage of Poverty rate numbers would not be affected.

10. There was a significant influence of variable DR to POV each 1.069171 (positive effect) on equation POV3; meaning that if there was an increase of 1 unit on the Dependency Ratio, the increase in the value of Percentage of the Poor population number respectively 1.069171; and if there was a decrease of 1 unit of Dependency Ratio, the decrease of Percentage of Poor Population numbers was 1.069171 .

11. There was a significant influence of variable SR to POV 0.5987416 (positive effect) on equation POV3; meaning that if there was an increase of 1 unit of Support Ratio, the increase in the value of Percentage of Poor population number was 0.5987416; and vice versa if there was a decrease of 1 unit of Support Ratio, the decrease of Percentage of Poor Population number was 0.5987416.

12. There was a significant influence of $\operatorname{lnGDRP}$ to POV -4.757184 (negative effect) on equation POV3; meaning that if there was an increase of one unit of the GDRP Natural logarithm, the decrease of Percentage of Poor Population numbers was 4.757184; and vice versa if there was a decrease of 1 unit of the GDRP Natural logarithm, the decrease of Percentage of Poor Population was 4.757184 .

13. There was no significant influence of variable TFR, EDU2, and DI to POV on equation POV3 equation; meaning that if there was an increase / decrease of 1 unit of Total Fertility rate, School duration average, and Percentage of Total Capital Investment, the percentage of Poverty rates would not be affected.

Thus mathematically, the formulation of multivariate regression models formed described as follows:

$\mathrm{POV}=-1,683586 \mathrm{TFR}+1,070551 \mathrm{DR}+0,2077121 \mathrm{EDU} 1+0,5236898 \mathrm{SR}$

$$
+0,020429 \mathrm{DI}+(-6,281613) \operatorname{lnGDRP}+\mathrm{e}_{1}
$$

$\mathrm{POV}=-1,24379 \mathrm{TFR}+1,085727 \mathrm{DR}+0,7749103 \mathrm{EDU} 2+0,5527158 \mathrm{SR}$

$+0,012182 \mathrm{DI}+(-6,049876) \ln \mathrm{GDRP}+\mathrm{e}_{2}$

$\mathrm{POV}=-0,28659 \mathrm{TFR}+1,06917 \mathrm{DR}+-0,12411 \mathrm{EDU} 3+0,59874 \mathrm{SR}+0,00042 \mathrm{DI}+$

$(-4,75718) \operatorname{lnGDRP}+\mathrm{e}_{3}$

Based on the test results in this study, the three equations, partially, the number of the working age population / total population (support ratio), number of the population aged $<15$ years / total population (dependency ratio), and the GDRP per capita significantly affected the poor population numbers.

The existence of a significant negative effect indicated that the increase of local or provincial revenues significantly influenced the reduction of the number of poor population number in Indonesia. This finding supported the theory of conventional economic development of conventional theory, the theory of economic growth from the thoughts from the Keynesian school, classical and neoclassical, the economic development based on changes in national output measures.

The finding that there was the significant positive relationship or positive significant influence of the number of populations aged $<15$ years of the total population to the number percentage of poor population. This findings in accordance with the concept of a demographic bonus, that the increase of dependency ratio (non-productive age) contributed positively to poverty (Bloom and Williamson, 1997; Orbeta, 2003; Nasir and Tahir, 2011). 
Table 2. Results of the $t$ test for coefficient significance of regression model with response variable POV.

\begin{tabular}{|c|c|c|c|c|c|}
\hline Equation & $\begin{array}{l}\text { Predictor } \\
\text { Variable }\end{array}$ & $\begin{array}{l}\text { Regression } \\
\text { Coefficient }\end{array}$ & $\begin{array}{l}\text { Standard } \\
\text { Error }\end{array}$ & Statistic t & P-value \\
\hline \multirow[t]{6}{*}{ POV1 } & TFR & $-1,683586$ & 2,572926 & $-0,65$ & 0,518 \\
\hline & DR & 1,070551 & 0,1869374 & 5,73 & $0,000 * * *$ \\
\hline & EDU1 & 0,2077121 & 0,1194586 & 1,74 & $0,092 *$ \\
\hline & SR & 0,5236898 & 0,1661941 & 3,15 & $0,004 * * *$ \\
\hline & DI & 0,020429 & 0,0426437 & 0,48 & 0,635 \\
\hline & $\operatorname{lnGDRP}$ & $-6,281613$ & 1,601157 & $-3,92$ & $0,000 * * *$ \\
\hline \multirow[t]{6}{*}{ POV2 } & TFR & $-1,24379$ & 2,688508 & $-0,46$ & 0,647 \\
\hline & DR & 1,085727 & 0,2086034 & 5,20 & $0,000 * * *$ \\
\hline & EDU2 & 0,7749103 & 1,747676 & 0,44 & 0,660 \\
\hline & SR & 0,5527158 & 0,1854865 & 2,98 & $0,005 * * *$ \\
\hline & DI & 0,012182 & 0,0456308 & 0,27 & 0,791 \\
\hline & $\operatorname{lnGDRP}$ & $-6,049876$ & 2,22504 & $-2,72$ & $0,010 * * *$ \\
\hline \multirow[t]{6}{*}{ POV3 } & TFR & $-0,28659$ & 2,91025 & $-0,10$ & 0,922 \\
\hline & DR & 1,06917 & 0,21837 & 4,90 & $0,000 * * *$ \\
\hline & EDU3 & $-0,12411$ & 0,30522 & $-0,41$ & 0,687 \\
\hline & SR & 0,59874 & 0,25400 & 2,36 & $0,025 * *$ \\
\hline & DI & 0,00042 & 0,04944 & 0,01 & 0,993 \\
\hline & $\operatorname{lnGDRP}$ & $-4,75718$ & 1,77619 & $-2,68$ & $0,012 * *$ \\
\hline
\end{tabular}

Source: Data Processing Result, 2016

$* * *$ Significant for significant level $(\alpha)$ of $1 \%$.

**Significant for significant level $(\alpha)$ of $5 \%$.

*Significant for significant level $(\alpha)$ of $10 \%$.

The findings that there was a significant positive relationship and a positive significant influence of the percentage the number of populations aged $>15$ years to the percentage of poor population, this finding not in accordance with the concept of demographic bonus. Unique phenomenon of these results was caused by a still high number of working-age population that did not get jobs, or jobless/unemployment and the working age population who work earned lower wages of decent living needs.

The results of this study also showed that using some measure indicators of different education (secondary school enrollment rate, the school duration average, and literacy rates), showed different effects, namely only education indicators in the form of secondary school enrollment rate affected poverty, It showed the access of the population of secondary school age (High School and Vocational High School, ages 16-18 years) affected positively to poverty in Indonesia. This phenomenon is empirically as fact in Indonesia caused by the condition that the working age population was still dominated by workers with primary school education level. The increasing numbers of population with high school education level was not accompanied by more employment absorb or occupation for those education level, so that the number of the unemployment rate at the level was higher than other education levels, it is based on data from the Indonesia Central Statistics Bureau. For instance, in 2010, the number jobless people or unemployment rate (in this case, the open unemployment) according to the highest level of graduation as follows: Elementary School below 3.81 percent Junior High School was 7.45 percent, Senior High School was 11.90 percent, Vocational High School was 11.87 percent, Diploma I / II / III was 12.78 percent and 11.92 percent was University. The high level 
of unemployment with a high school education can result in less access to the income obtained for better life or decent standard of living.

While the average years of schooling which was the number of years spent by population aged 15 years and above to pursue any type of formal educations, did not show any significant effect on poverty, in other words, the higher or longest the number the school duration, the higher the level of population education achieved did not effect on number of poor people of the alleviation poverty in Indonesia. This finding contradicts with the previous research by Awan et al., 2011. This is also the case of literacy rate variable, the findings showed that the ability of the population of the region that opened to knowledge did not affect the number of poverty subtraction in Indonesia. Whereas it is believed that literacy is the right of everyone who can have a positive impact on social and economic life, for instance in term of poverty alleviation. Since it is supporting their ability to carry our daily activities. However, this finding contradicts to those ideas, and support the idea that educational attainment is a poor proxy for literacy (Smith \& Greenway, 2015)

\section{Conclusion}

Tests on this study concludes that there were significant simultaneous significant predictor variables of equations used to variable response in the form of poverty. Unfortunately, partially only variable support ration (the percentage of the working age population / total population), variable dependency ratio (the percentage of the working age population / total population ) and provincial revenue in the form of regional gross domestic product per capita that have effect on poverty (reduction of poverty), as an indicator of sustainability development, these findings supported the notion that economic development was influenced by changes or improvements in measures of national output.

Specifically related to the specific measures of education indicators used, showed empirical phenomena different to the alleged expected, the three indicators of educational used only the secondary enrollment rate that affected poverty (number of poor people) negatively, indicating that an increasing number of people's access to secondary education, led to an increase in number of poor population, which caused the high level of unemployment by level of education.

Based on the findings in this study, a recommendation for the government to be more serious to create a conducive labor market conditions, in term of in absorbing more or enlarge the job opportunity and reducing unemployment. More over a recommendation for the government to be more serious in improving and enhancing human capital as part of efforts to increase manpower through education in term of the quality of education in order to achieve the economic situation better, in the form of sustainability economic development, since there is no effect of average years of schooling and the school enrollment rate has negative significance effect.

Society also need to raise awareness for the start themselves in creating jobs not only for themselves, but also for the community. Since we need to realize poor economic development will impact the long-term employment for development in Indonesia. This condition needs to aware by various party, i.e.: business, industry as the private institution, government as the nation institution and community groups.

Furthermore, we also recommend doing further research using different educational indicators, due to the limitation of this research. For instance, by comparing levels of different indicator of education, hence it can be finding a number of new research results that are contribute to the development of body of knowledge, useful in expanding horizons and develop the theory and knowledge that can be used as a tool in solving problems.

\section{References}

Awan, M. S., N. Malik, H. Sarwar and M. Waqas. 2011. Impact Education on Poverty Reduction. Munich Personal RePEc Archive Paper, No. 31826. Online at https://mpra.ub.unimuenchen.de/31826/. Date accessed 15 October 2018, 
Bloom, D. E. and J. G. Williamson. 1997. 'Demographic Transitions and Economic Miracles in Emerging Asia', NBER Working Paper Series; Working Paper 6268: 1-48. National Bureau of Economic Research. http://ww.nber.org/papers/w6268, accessed date24 September 2013.

Epure, M. 2015. Book Review (Peet, R., Hartwick E. - Theories of Development: Contentions, Arguments, Alternatives). Journal of Economics Developments, Environment and People, Vol. 4 (4): 76-79.

Feng, W. 2011. 'The End of 'Growth with Equity'? Economic Growth and Income Inequality in East Asia'. Asia Pasific Issues. Analysis from the East-West Center, No.101.

Kuncoro, M. 2010. Masalah, Kebijakan, dan Politik Ekonomika Pembangunan [Problems, Policies and Politics of Economic Development]. Penerbit Erlangga. Jakarta.

2013. Masalah, Kebijakan, dan Politik Ekonomika Pembangunan [Problems, Policies and Politics of Economic Development]. Penerbit Erlangga. Jakarta.

Mazurov, Yury L., and Vladimir S. Tikunov. 2006. 'How to Measure Sustainable Development: A View from Russia'. International Journal of Sustainable Development and World Ecology, Vol. 13 (6), pp.: 525-537.

Nasir, J. A. dan M. H. Tahir. 2011. 'A statistical assessment of demographic bonus towards poverty alleviation', Pakistan Journal of Commerce and Social Sciences; vol. 5 (1): 01-11.

Orbeta, A. C, Jr., 2003. 'Population and Poverty: A Review of the Links, Evidence and Implications for the Philippines', Philippine Journal of Development, Vol. 30 (2): 195-277; ABI/INFORM, accessed date 20 March 2014.

Silipo, L., 2009. 'The truth about demographic dividend in Asia. Flash Economic's, ECONOMIC RESEARCH; No.541;NATIXIS; GROUPE BPCE:1-12 cib.natixis.com/flushdoc.aspx?id=49917, accessed date 21 September 2013.

Smith, E., \& Greenway. 2015. Educational attainment and adult literacy: A descriptive account of 31 Sub-Saharan Africa countries. Demographic Research, Vol. 33, article 35: 10151034,https://www.demographic-research.org/volumes/vol33/35/33-35.pdf, accessed date 15 October 2018. 